\title{
Quantity Distributed per Reporting Interval
}

National Cancer Institute

\section{Source}

National Cancer Institute. Quantity Distributed per Reporting Interval. NCI Thesaurus.

Code C106325.

Quantity of items distributed in a reporting period. 